\title{
Perancangan Sistem Pengolahan Data Tabungan Santri Berbasis Web Pada Yayasan Al-Mujammi Al Islami
}

\author{
Syafiq Najiyyullah ${ }^{1}$, Ramadhan Yoga Wardana ${ }^{2}$, Faruq Prasetyo ${ }^{3}$, Firmansyah Lubis ${ }^{4}$, \\ Rahmat Ferdiansyah ${ }^{5}$, Mulia Rahmayu ${ }^{6}$ \\ 1,2,3,4,5,6 Universitas Nusa Mandiri \\ Jl. Kramat Raya No. 18 Jakarta Pusat \\ e-mail: ${ }^{1}$ syafiq.n678@gmail.com, ${ }^{2}$ yogawardhana99@gmail.com, \\ ${ }^{3}$ faruq27prasetyo@gmail.com, ${ }^{4}$ lubisfirmansyah12@gmail.com, \\ 5rahmatferdiansyah05@gmail.com, ${ }^{6}$ mulia.mlh@nusamandiri.ac.id
}

\begin{abstract}
Abstrak
Saat ini sistem informasi tabungan santri yang berjalan pada yayasan al-mujammi' al-islami masih berjalan manual sehingga dapat memungkinkan beberapa masalah dalam menangani proses pembayaran serta perhitungannya. Solusi pengabdian masyarakat ini ialah membuat sistem pengolahan data tabungan santri berbasis web, dan diharapkan dengan adanya sistem baru, ini dapat mengoptimalkan sistem komputer yang ada dalam memproses tabungan, sehingga meminimalisir adanya kesalahan dalam penginputan atau perhitungan untuk menghasilkan data yang lebih tepat dan akurat. Sedangkan perancangan sistem pengolahan data tabungan santri berbasis web menggunakan bahasa pemrograman PHP dan database $M y S Q L$. Dan metode yang digunakan adalah metode waterfall atau biasa disebut air mancur, Dan ini metode ini sering digunakan karena pengaplikasiannya mudah.
\end{abstract}

Kata Kunci: Sistem Informasi Tabungan, PHP, MySQL

\begin{abstract}
Currently the santri savings information system that runs on the al-mujammi 'al-islami foundation is still running manually so that it can allow some problems in handling the payment process and its calculations. This community service solution is to create a webbased student savings data processing system, and it is hoped that with the new system, this can optimize the existing system in processing savings, thereby minimizing errors in input or calculations to produce more precise and accurate data. While designing a web-based student savings data processing system using the PHP programming language and MySQL database. And the method used is the waterfall method or commonly called the fountain, and this method is often used because its application is easy.
\end{abstract}

Keywords: Savings Information System, PHP, MySQL

\section{Pendahuluan}

Pada saat ini perkembangan teknologi di zaman sekarang sudah mengalami kemajuan di kehidupan manusia. Dalam bidang teknologi informasi yang menggunakan sistem komputer sudah dikenal di kalangan masyarakat sampai saat ini dan banyak software yang bisa digunakan sebagai sistem pengolahan data untuk menghasilkan suatu informasi akurat dan efisien di bidang ekonomi maupun pendidikan (Riyanto et al., 2019).

Dalam bidang ekonomi dan pendidikan tentunya berkaitan dengan kebiasaan turun temurun dari orang tua adalah kebiasaan menabung sejak usia dini untuk melatih serta mendidik 
masyarakat terutama anak anak supaya bisa mengatur keuangan dengan bijak agar dapat mengatasi terjadinya krisis ekonomi. Kebanyakan dari orang tua untuk membiasakan anaknya belajar menabung ialah dengan mempercayakan sebuah lembaga pendidikan seperti yayasan ataupun sekolah (Riyanto et al., 2019).

Begitupun pada salah satu lembaga pendidikan Yayasan Al-Mujammi’ Al Islami adalah salah satu Yayasan yang tepatnya beralamat di Jl. Bojong Raya rt002/04 Rawa Buaya Kecamatan Cengkareng, Jakarta Barat, kode pos 11740. Sebagian besar santri merupakan warga dari kampung Bojong Raya. Di dalamnya terdapat beberapa pengurus yaitu ketua, bendahara, sekretaris, humas, litbang, pendidikan, kerja sama. Semua kegiatan belajar mengajar dilakukan oleh santri yang juga bahkan di berbagai kegiatan pengolahan data juga dilakukan oleh santri yang mempunyai aktivitas diluar Yayasan yaitu sebagai siswa/siswi. Dalam hal ini, kegiatan pengolahan tabungan di Yayasan Al-Mujammi' Al Islami masih menggunakan sistem manual dengan cara tulis tangan di buku tabungan oleh pengurus, pengolahan datanya berupa pembayaran syahriah santri. Dan cara tersebut dinilai kurang efektif sehinngga berpotensi menimbulkan kesalahan yang tidak diinginkan oleh pengurus. Hal tersebut menjadi sebuah permasalahan yang harus diperbaiki dalam sistem pengolahan data tabungan tersebut (Anwar, 2020).

Dengan dibuatkannya website tabungan santri berbasi web ini, diharapkan dapat mempermudah pengurus dalam proses penginputan data tabungan Yayasan Al-Mujammi' AlIslami, sehingga pengurus dapat membuat laporan tanpa harus menghitung secara manual satu per satu data transaksi pembayaran. Sistem pengolahan tabungan ini dibuat dengan menggunakan PHP (pear hypertext prepocessor) sebagai bahasa pemograman, Visual studio code sebagai perangkat pendukung, dan MySql sebagai database management system. Sehingga nantinya bisa menghasilkan sebuah sistem yang dapat digunakan oleh pengurus dalam mengelola seluruh proses transaksi tabungan Yayasan Al-Mujammi' Al-Islami dan membuat laporan bulanan maupun tahunan secara mudah (Anwar, 2020).

\section{Solusi Permasalahan}

Untuk solusi permasalahan dalam penyusunan skripsi ini berupa :

1. Sistem pengolahan data tabungan santri berbasis web yang dapat menggantikan sistem tabungan manual pada Yayasan Al-Mujammi' Al Islami.

2. Untuk sistem tabungan santri yang dioperasikan secara online ini nantinya akan bermanfaat bagi pengurus dan santri serta meningkatkan kinerja, dan kualitas pengolahan data tersebut.

\section{Konsep Dasar Sistem Informasi}

Menurut Anis Mashduroratun, "Sistem adalah suatu keseluruhan yang terangkai yang terdiri atas komponen-komponen di mana antara komponen yang satu dengan yang lainnya saling berkaitan atau berhubungan dan apabila salah satu komponen terpengaruh akan mempengaruhi keseimbangan sistem secara keseluruhan" (Mashdurohatun, 2018).

Menurut Lukman Hakim, menyatakan bahwa "Informasi adalah hasil akhir dari serangkaian proses aktivitas pengumpulan data, pengolahan, dan penginterprestasian yang dengannya dapat digunakan sebagai alasan untuk membuat keputusan pengembangan suatu organisasi” (Hakim, 2019). 


\section{Metode}

Tahapan kegiatan yang dilakukan untuk menyelesaikan permasalahan pengabdian masyarakat di Yayasan Al-Mujammi’ Al Islami:

\section{a. Persiapan (engagement)}

Tahapan ini meliputi persiapan pengabdian masyarakat dan persiapan lapangan. Pada persiapan pengabdian masyarakat, dilaksanakan dengan kesamaan persepsi antara anggota kelompok dengan jenis pendekatan yang digunakan sebagai upaya pengabdian kepada masyarakat. Persiapan lapangan dilaksanakan melalui studi kelayakan mengenai tempat yang akan dijadikan sebagai sasaran pelakasanaan pengabdian.

\section{b. Pengkajian (assessment)}

Merupakan kegiatan untuk mengidentifikasi permasalahan pada kebutuhan kelompok sasaran. Pada tahap ini, secara aktif melibatkan masyarakat agar masyarakat mampu mengidentifikasi masalah yang sedang mereka alami. Pengabdian masyarakat berperan sebagai penyedia fasilitas untuk masyarakat dalam menyusun permasalahan yang ada.

\section{c. Perencanaan program dan kegiatan (planning)}

Pada tahapan ini pengabdian masyarakat membutuhkan peran masyarakat untuk berpikir tentang masalah yang mereka hadapi dan bagaimana cara mengatasinya. Dalam mengatasi permasalahan yang ada, masyarakat diharapkan dapat memikirkan program dan kegiatan apa saja yang dapat dilaksanakan. Beberapa program harus menggambarkan kelebihan maupun kekurangannya, sehingga program yang dipilih nanti dapat menunjukkan program yang paling efektif untuk mencapai sebuah tujuan pengabdian kepada masyarakat. Untuk kelebihannya ialah keakurasian data yang tinggi dan terintegrasi dengan sistem lainnya, sedangkan kekurangannya ialah tingginya harga pembuatan sebuah perancangan program. Selain itu, sistem tabungan santri juga sangat bergantung pada jaringan internet.

\section{d. Pemformulasian rencana Aksi (Formulating action plan)}

Tahapan ini pengabdian masyarakat memutuskan rencana dan kegiatan yang nantinya akan diambil untuk mengatasi permasalahan yang ada. Oleh karenanya, pengabdian masyarakat membuat sebuah pemroraman berupa sistem pengolahan data tabungan santri berbasis web yang nantinya bisa langsung diaplikasikan oleh pihak Yayasan Al-Mujammi' Al Islami. Dikarenakan masih dalam kondisi pandemi Covid-19 untuk pelaksanaan kegiatan di Yayasan Al-Mujammi' Al Islami akhirnya ditiadakan, dan untuk pengaplikasian program nanti peneliti akan mencoba melakukan uji coba tentang penggunaan sistem tabungan santri hanya kepada guru Yayasan Al-Mujammi’ Al Islami saja.

\section{e. Pelaksanaan Program dan Kegiatan (implementation)}

Dalam upaya untuk mengadakan pelaksanaan program pengabdian masyarakat, tentu masyarakat diharapkan dapat mengikuti serta menjaga keberlangsungan program yang akan dikembangkan. Dalam tahapan pengabdian masyarakat ini merupakan hal yang sangat penting, karena terkadang sesuatu yang sudah direncanakan dengan baik tidak menutup kemungkinan bisa saja melenceng saat di lapangan. Oleh karena itu, supaya seluruh anggota dapat memahami program secara jelas perihal sasaran dan maksud tujuannya, maka program ini perlu disosialisasikan, sehingga dalam pengoperasiannya tidak mengalami kendala yang berarti. Dan untuk pelaksanaan kegiatannya berlangsung selama 5 hari, dari tanggal 20 Juli sampai dengan 26 juli di yayasan Al-Mujammi Al Islami. 


\section{f. Evaluasi (evaluation)}

Pada tahapan evaluasi ini, sangat diharapkan dapat mengetahui secara jelas seberapa besar tingkat keberhasilan program ini dapat dicapai, sehingga dapat diketahui kendala-kendala yang ada pada kesempatan berikutnya dapat diantisipasi untuk memecahkan permasalahan atau kendala yang akan dihadapi.

\section{Hasil Dan Pembahasan}

Pelaksanaan kegiatan pengabdian masyarakat yang bertempat pada Yayasan Al-Mujammi' telah menghasilkan sistem pengolahan data tabungan santri. Saat ini Proses penyetoran tabungan masih membutuhkan peran wali kelas, yaitu ketika santri ingin menabung mereka harus menyerahkan uang kepada wali kelas dan dilanjutkan ke bendahara tabungan atau tata usaha untuk diinput ke sistem tabungan santri sebagai transaksi penyetoran. Dan untuk pengambilan tabungannya dapat diambil kapanpun dengan datang ke wali kelas atau bendahara.

\begin{tabular}{|c|c|}
\hline Sistem Manual & Sistem Terkomputerisasi \\
\hline $\begin{array}{l}\text { Dalam permasalahan ini, kinerja dari sistem } \\
\text { tabungan di Yayasan Al-Mujammi' Al Islami } \\
\text { kurang efektif dan efisien jika dilihat dari } \\
\text { hasil respon time. Misalkan saja dalam } \\
\text { pembuatan laporan tabungan. Pekerjaan tersebut } \\
\text { membutuhkan waktu yang lama karena } \\
\text { pembuatan laporan tersebut dilakukan dengan } \\
\text { cara tulis tangan ke dalam buku. Dalam sistem } \\
\text { yang berjalan saat ini, informasi yang } \\
\text { dihasilkan tidak akurat dan terdapat } \\
\text { kesalahan dalam penulisan data. }\end{array}$ & $\begin{array}{l}\text { Sistem tabungan santri berbasis web ini } \\
\text { merupakan perancangan sistem yang } \\
\text { dapat memudahkan guru dan santri } \\
\text { mengenai permasalahan pengolahan data } \\
\text { tabungan. Sistem pengolahan data } \\
\text { tabungan ini juga dapat menghasilkan } \\
\text { laporan dan tentunya akurat dan afisien, } \\
\text { dikarenakan data tabungan sudah di olah } \\
\text { oleh sistem dan direkap dengan baik. }\end{array}$ \\
\hline $\begin{array}{l}\text { Sistem tabungan pada Yayasan Al-Mujammi' } \\
\text { Al Islami yang masih menggunakan cara } \\
\text { manual, menyebabkan pembengkakan biaya. } \\
\text { Hal itu terjadi karena dalam pemrosesan data } \\
\text { dan pembuatan laporan membutuhkan kertas, } \\
\text { buku, tinta, dan alat tulis lainnya. Peralatan } \\
\text { tersebut dibutuhkan dalam jumlah banyak } \\
\text { sehingga dapat menyebabkan pemborosan pihak } \\
\text { sekolah. }\end{array}$ & \multirow[t]{2}{*}{$\begin{array}{l}\text { Dengan adanya sistem pengolahan data } \\
\text { tabungan santri berbasis web ini guru } \\
\text { tidak perlu mencatatnya lagi ke dalam } \\
\text { buku dan untuk santri juga tidak usah } \\
\text { khawatir soal data tabungannya masing- } \\
\text { masing kare sudah di input oleh sistem itu } \\
\text { sendiri. }\end{array}$} \\
\hline $\begin{array}{l}\text { Saat pencatatan data sering terjadi adanya } \\
\text { kesalahan. Sehingga pemrosesan data dan } \\
\text { hasil laporan yang telah dibuat juga akan } \\
\text { salah. Hal itu terjadi karena faktor manusia } \\
\text { yang sering lupa dan kurang teliti. . }\end{array}$ & \\
\hline
\end{tabular}




\section{ABDITEKNIKA}

Jurnal Pengabdian Kepada Masyarakat

Berikut keberhasilan penerapan sistem tabungan santri pada yayasan Al-Mujammi’ Al Islami:

a. Tampilan menu login

Tampilan menu login untuk para admin/petugas masuk ke halaman aplikasi.

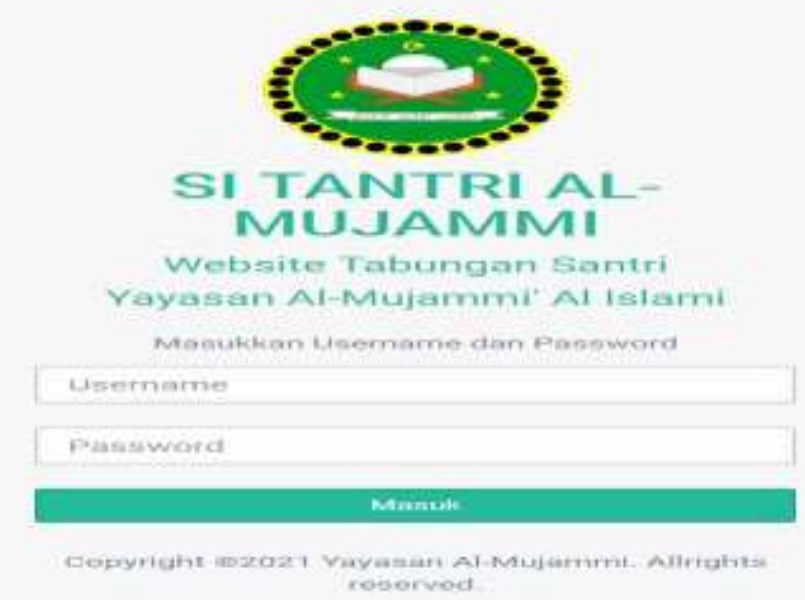

Gambar IV.4 Tampilan Menu Login

b. Tampilan Menu Utama

Tampilan menu utama berisi tentang beberapa menu di dalamnya.
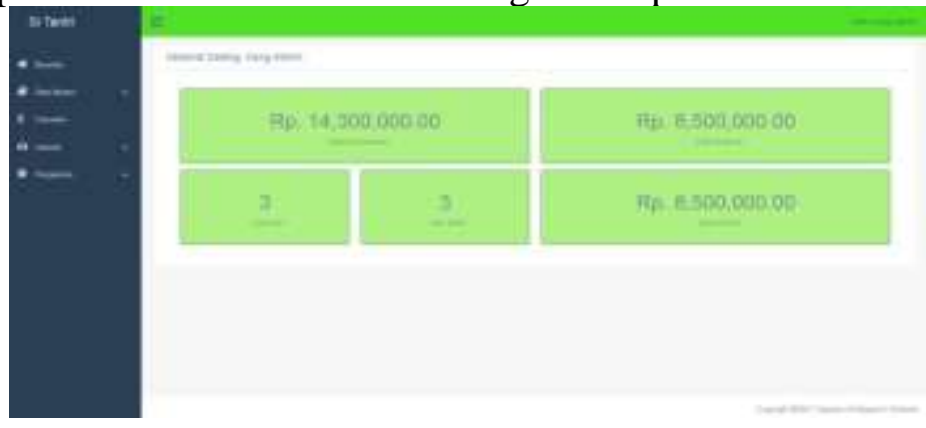

Gambar IV.5 Tampilan Menu Utama

c. Tampilan Menu Data Nasabah

Pada halaman ini terdapat nama-nama santri sesuai dengan saldo masing-masing, di dalam menu ini juga bisa menambahkan data baru santri, edit dan hapus data.

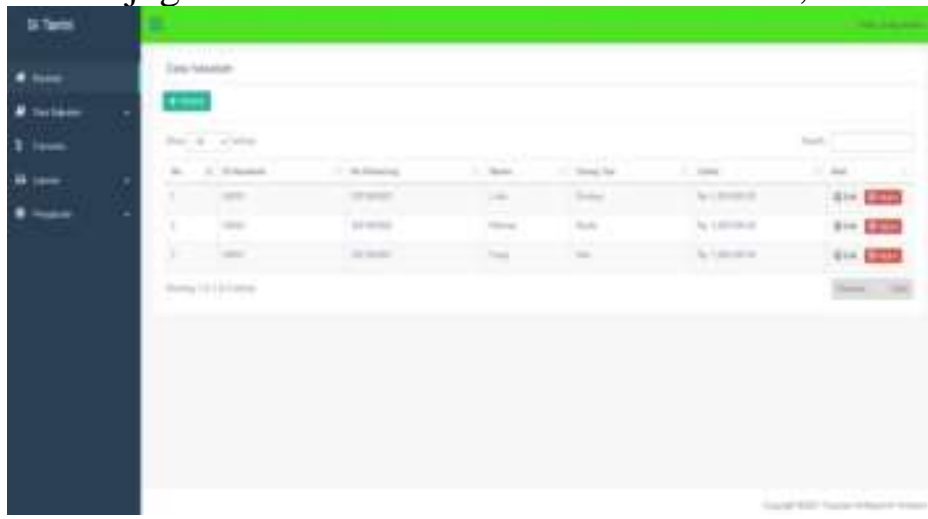

Gambar IV.6 Tampilan Menu Data Nasabah 


\section{d. Tampilan Menu Transaksi}

Pada menu transaksi ini terdapat menu setoran tunai, penarikan tunai, saldo keseluruhan, dan nama-nama nasabah beserta saldo yang tersimpan.

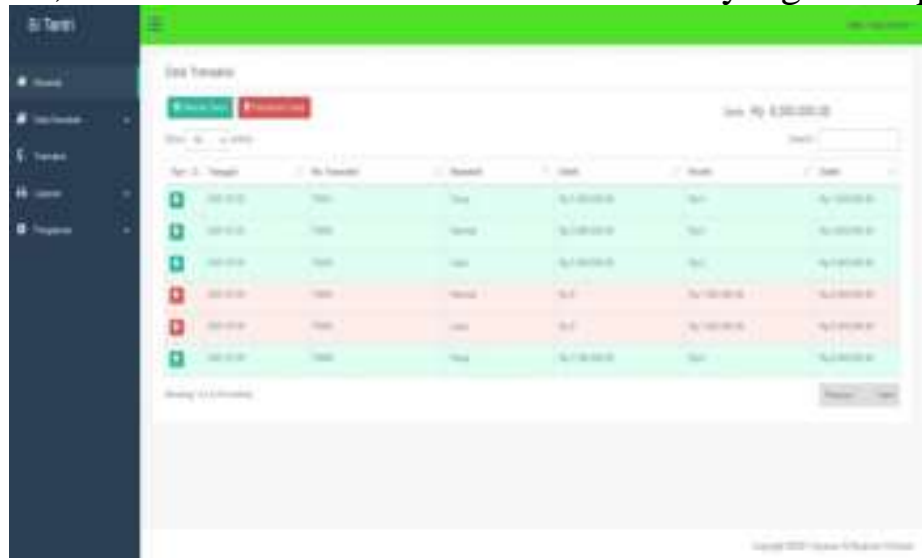

Gambar IV.7 Tampilan Menu Transaksi

e. Tampilan Menu Setoran Tunai

Pada menu setoran tunai ini terdapat form input nominal jumlah setoran tunai, terlebih dahulu memasukkan nomor rekening nasabah yang akan di input.

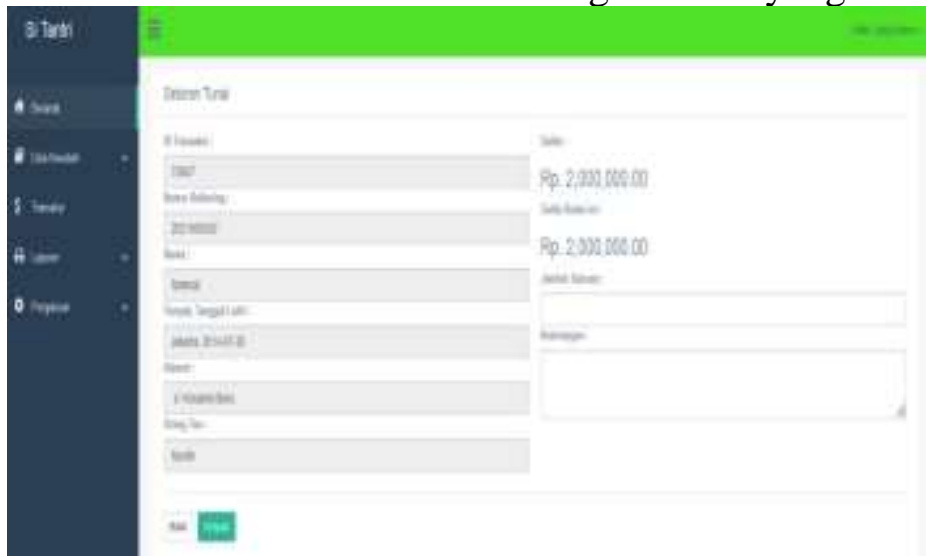

Gambar IV.8 Tampilan Menu Setoran Tunai

f. Tampilan Menu Penarikan Tunai

Pada menu penarikan tunai terdapat form penarikan dengan memasukkan nominal uang yang akan diambil.

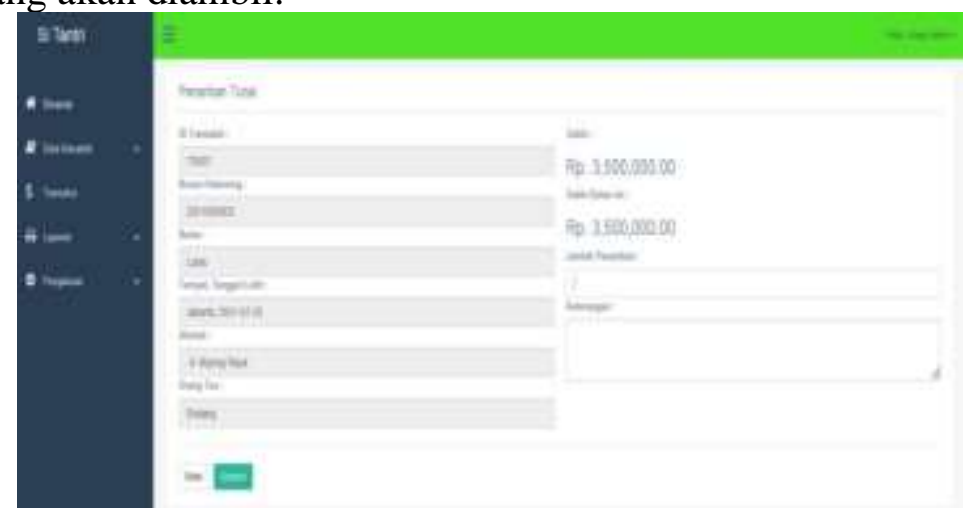

Gambar IV.9 Tampilan Menu Penarikan Tunai 


\section{g. Tampilan Menu Laporan Transaksi}

Pada tampilan menu ini berisi laporan yang akan di cetak sesuai dengan tanggal yang dibutuhkan, cetak laporan pernasabah atau cetak priode.

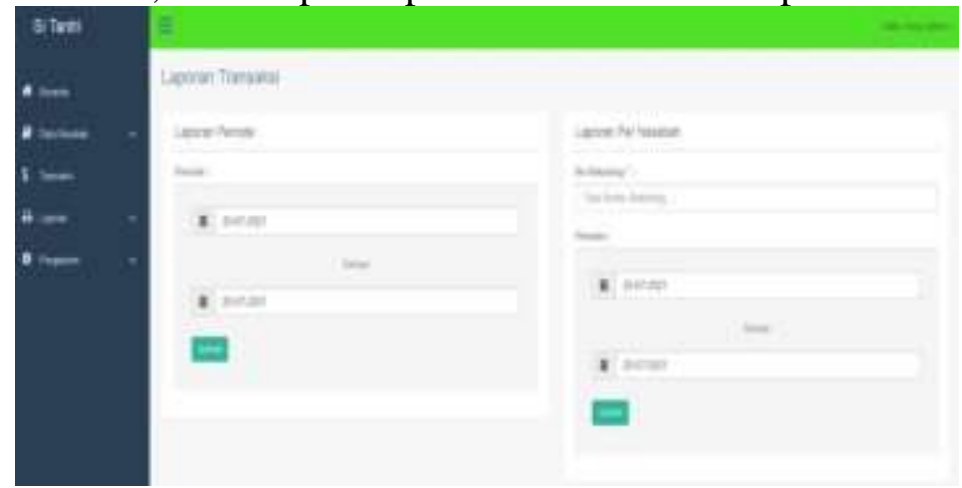

Gambar IV.10 Tampilan Menu Laporan Transaksi

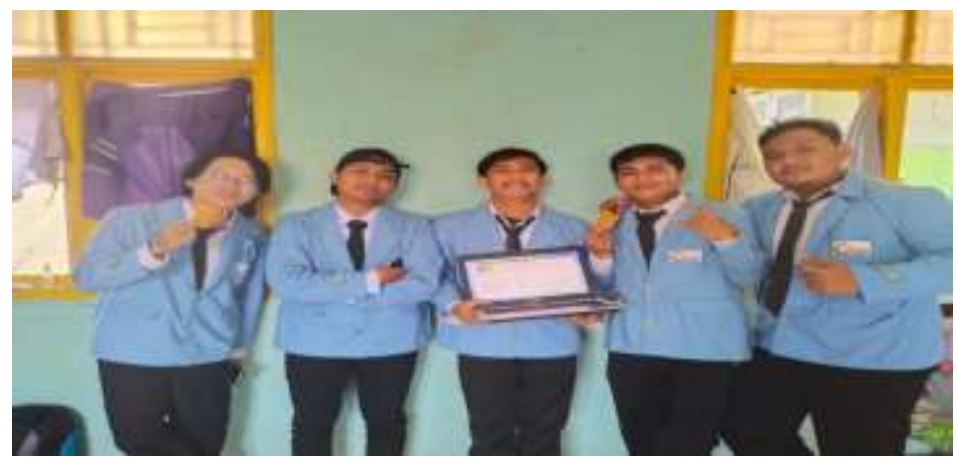

Gambar IV.11 Kegiatan Pengabdian

\section{Kesimpulan}

Berdasarkan rumusan masalah mengenai perancangan sistem informasi tabungan santri di Yayasan Al-Mujammi Al Islami dengan menggunakan web maka dapat disimpulkan bahwa, sistem informasi tabungan santri yang terkomputerisasi dapat berupa perancangan sistem usulan,yang terdiri dari use case diagram, activity diagram, ERD (Entity Relationship Diagram). Sedangkan untuk perancangan user interface nya terdiri dari, tampilan menu login, tampilan menu utama, tampilan menu nasabah, tampilan menu transaksi, tampilan menu setoran tunai, tampilan menu penarikan tunai, tampilan menu laporan transaksi. Dan untuk pembahasannya ialah untuk membantu guru dan santri menyelesaikan permasalahan yang sering terjadi saat pencatatan data santri, transaksi penyetoran dan penarikan yang dilakukan secara sistematis, sehingga data aman dan akurat dengan tidak adanya data yang duplikasi serta tersedia menu pembuatan laporan sehingga memudahkan pembuatan laporan dalam kurun waktu tertentu yang langsung dapat dicetak, dan sistem yang dirancang berjalan secara efektif dan efisien. Proses pengolahan data serta pencarian data menjadi lebih mudah. Dengan adanya sistem informasi tabungan santri ini, guru dapat dengan cepat dan akurat menyajikan laporan tabungan kepada bendahara yayasan.

\section{Daftar Pustaka}

Anwar, I. M. (2020). Sistem Pengelolaan Keuangan Pondok Pesantren Berbasis Website Menggunkan Arsitektur Model-View- Controller (MVC) (Studi Kasus: Pondok Pesantren 'Inayatullah Yogyakarta). Mvc. 


\section{ABDITEKNIKA}

Jurnal Pengabdian Kepada Masyarakat

Volume 1 Nomor 2 Oktober 2021

ISSN 2775-1694

Hakim, L. (2019). Prinspip-prinsip dasar sistem informasi manajemen (Issue 1).

Mashdurohatun, A. (2018). Hak Cipta Atas Buku Model Fair Use/Fair Dealing. In PT RajaGrafindo Persada.

Riyanto, A., Syabaniah, R. N., Selviana, S., \& Marsusanti, E. (2019). Pemanfaatan Aplikasi Tabungan Siswa Berbasis Web Pada Pendidikan Anak Usia Dini (PAUD). Syntax: Jurnal Informatika, 8(2), 101. https://doi.org/10.35706/syji.v8i2.2162

A. Hilir, Pengembangan Teknologi Pendidikan dan Peranan Pendidik dalam Menggunakan Media Pembelajaran. Klaten, 2021.

B. Walidaini and A. M. Muhammad Arifin, "Pemanfaatan Internet Untuk Belajar Pada Mahasiswa," J. Penelit. Bimbing. dan Konseling, vol. 3, no. 1, 2018, doi: 10.30870/jpbk.v3i1.3200.

Fitri Ayu and Nia Permatasari, "perancangan sistem informasi pengolahan data PKL pada divisi humas PT pegadaian,” J. Infra tech, vol. 2, no. 2, pp. 12-26, 2018.

Ismah, Pemrograman Komputer Dasar-Dasar Phyton. Jakarta, 2017.

N. Sany and E. Indriani, "Sistem Informasi Tabungan Siswa Berbasis Web Pada Sekolah Menengah Kejuruan ( SMK ),” vol. 4, no. 2, pp. 244-256, 2018.

M. Melyanti, R., Iqbal, M., "Sistem Informasi Manajemen Penelitian Dan Pengabdian Masyarakat Di Bagian P3M (Studi Kasus: Stmik Hang Tuah Pekanbaru)," J. Ilmu Komput., vol. 9, no. 2, pp. 165-176, 2020. 